\title{
Letter to the editor regarding "Comparison of clinical outcomes between arthroscopic debridement and conservative treatment of primary adhesive capsulitis of the hip"
}

\author{
Tomonori Shigemura ${ }^{1}$ (DD
}

Received: 26 June 2020 / Accepted: 3 July 2020 / Published online: 9 July 2020

(C) SICOT aisbl 2020

I read with great interest an article titled "Comparison of clinical outcomes between arthroscopic debridement and conservative treatment of primary adhesive capsulitis of the hip" by Lim et al. [1] published in the June 2020 issue of the journal and would like to congratulate the authors for their study. Authors performed a retrospective case-control study that assessed the clinical outcomes and change of range of motion (ROM) between patients with adhesive capsulitis of hip $(\mathrm{ACH})$ who underwent arthroscopic capsular release (ACR) and those who underwent conservative treatment at a minimum follow-up of two years. Although they have touched a highly pertinent topic in a scientific manner, the study has brought important issues that I would like to communicate with the authors.

1. Authors concluded that patients with severe limitation of ROM are possible candidates of ACR. However, there was no significant difference in the degree of abduction between the operation group and the conservative group during follow-up periods, and there was also no significant difference in the degree of external rotation between the two groups during follow-up periods except for the post-operative six weeks. I think these results are inconsistent with the authors' conclusion.

2. ACR is a common treatment for adhesive capsulitis of the shoulder (ACS). Yanlei et al. reviewed prospectively collected data of 56 consecutive patients with ACS who underwent ACR, and patients with diabetic mellitus (DM) had poorer internal rotation $(p=0.000)$, forward flexion $(p=0.035)$, and poorer post-operative Constant Shoulder score $(p<0.05)$ [2]. How many patients with DM were included in the authors' study? I think that the results may change if patients with and without DM are examined separately, because the clinical characteristics of $\mathrm{ACH}$ are similar to those commonly attributed to this condition in the shoulder [3].

\section{Compliance with ethical standards}

Conflict of interest The author declares that he has no conflict of interest.

\section{References}

1. Lim JY, Djaja YP, Won YS, Jang EC, Kim JY, Ha YC (2020) Comparison of clinical outcomes between arthroscopic debridement and conservative treatment of primary adhesive capsulitis of the hip. Int Orthop. https://doi.org/10.1007/s00264-020-04659-x

2. Yanlei GL, Keong MW, Tijauw Tjoen DL (2019) Do diabetic patients have different outcomes after arthroscopic capsular release for frozen shoulder? J Orthop 16:211-215. https://doi.org/10.1016/j.jor. 2019.02.003

3. Byrd JW, Jones KS (2006) Adhesive capsulitis of the hip. Arthroscopy. 22:89-94. https://doi.org/10.1016/j.arthro.2005.10. 009

Publisher's note Springer Nature remains neutral with regard to jurisdictional claims in published maps and institutional affiliations.

Tomonori Shigemura

tshigepon@yahoo.co.jp

1 Department of Orthopaedic Surgery, Teikyo University Chiba Medical Center, 3426-3 Anesaki, Ichihara, Chiba 299-0111, Japan 